\title{
Editorial
}

\section{Antarctica and the IPCC}

$\mathrm{T}$ he fourth assessment of the Intergovernmental Panel on Climate Change (IPCC) is published. It describes the current state of knowledge on climate change (Working Group I), how it impacts our lives and environment (Working Group II) and how we can avoid the worst consequences of climate change (Working Group III). For the scientific community, the Working Group I report (The Physical Science Basis) is undoubtedly of the greatest professional interest.

Sadly, publication was stretched over several months with unfortunate consequences. In February, the Summary for Policy Makers became publicly available. This took long and hard negotiations at government level to agree the final wording and conclusions, so a neutral spectator could conclude that, at least in this instance, the IPCC science has been highly politicized in presentation. True or not, the Summary for Policy Makers is too condensed and difficult to read; it is certainly not the authoritative document some claim it to be. The technical summary provides more background, and is therefore a little better.

Only several months later was the full Working Group I report finally published online (www.ipcc.ch). In spite of its 1000 pages, it is a much easier read than the summaries. With an impeccable layout, extensive room for Frequently Asked Questions and a clear, non-formal writing style, it sets a new standard for authoritative scientific reporting. An additional advantage is that all 11 chapters can be read independently of each other. In spite of this it seems only too likely that very few policy makers will now be prepared to read even part of the full document. This could -and should- have been avoided by publishing the full report and the summaries simultaneously.

So what role does Antarctic science play in the new assessment? An important one, in several respects. To start with the past: the EPICA ice core from Dome C in East Antarctica now provides the longest chronology of long-lived greenhouse gas concentrations. It makes painfully clear that the present-day levels and rates of increase are unprecedented over the last 800000 years. Antarctic ice cores also provide important clues as to the mechanisms of inter-hemispheric heat exchange and the global cycles of carbon and methane.

As for the present: contemporary climate change in Antarctica is elusive, in contrast to the dramatic changes observed in the Arctic. Moreover, those changes that are being observed in Antarctica's atmosphere and cryosphere are as yet unexplained. For example, none of the coupled ocean-atmosphere models can explain the strong warming in the Antarctic Peninsula. None of the existing glacier and ice sheet models is capable of simulating the disintegration of ice shelves in the northern Peninsula, or the acceleration and thinning of grounded glaciers that followed. And whether the thinning of glaciers in the Amundsen Sea sector is a recent or ongoing phenomenon cannot be answered with any certainty.

Geological evidence shows that in the not too-distance past, parts of the Antarctic ice sheet must have been significantly smaller than today, in a climate only several degrees warmer. This brings us to the all-important question: how will the enormous Antarctic ice sheet behave in the future and how will sudden changes in its dynamics contribute to sea level rise? The IPCC authors considered our knowledge on this topic so inadequate that they excluded it from the uncertainty estimate for future sea level rise. This is a painful message for Antarctic glaciologists, who are facing a formidable scientific challenge to fill this gap.

My hope is that they will consider Antarctic Science as a suitable forum for their undoubtedly spectacular discoveries, providing my replacement with plenty of editorial work.

Michiel VAN DEN BRoEKE 